\title{
Oral Films: A Comprehensive Review
}

\author{
*Muhammad Bilal Hassan Mahboob ${ }^{1,2}$, Tehseen Riaz ${ }^{1,2}$, Muhammad Jamshaid ${ }^{1}$, Irfan Bashir ${ }^{1,2}$ and Saqiba Zulfiqar ${ }^{1,2,3}$ \\ ${ }^{1}$ Faculty of Pharmacy, University of Central Punjab Lahore, Pakistan \\ ${ }^{2}$ Foundation for Young Researchers, Pakistan \\ ${ }^{3}$ Shoukat Khanum Memorial Cancer Hospital \& Research Centre, Lahore, Pakistan
}

\begin{abstract}
In the late 1970s, rapid disintegrating drug delivery system was developed as an alternative to capsules, tablets and syrups for geriatric and pediatric patients having problems in swallowing. To overcome the need, number of orally disintegrating tablets which disintegrate within one minute in mouth without chewing or drinking water were commercialized. Then later, oral drug delivery technology had been improved from conventional dosage form to modified release dosage form and developed recently rapid disintegrating films rather than oral disintegrating tablets. Oral disintegrating film or strips containing water dissolving polymer retain the dosage form to be quickly hydrated by saliva, adhere to mucosa, and disintegrate within a few seconds, dissolve and releases medication for oromucosal absorption when placed in mouth. Oral film technology is the alternative route with first pass metabolism. This review give a comprehensive detail of materials used in ODF, manufacturing process, evaluation tests and marketed products.
\end{abstract}

Key Words: Oral disintegrating film, oral strip, pediatric and geriatric patients.

\section{INTRODUCTION}

Oral administration is the most preferred route due to relieve of ingestion, pain reduction, to accommodate various types of drug candidates and the most important patient compliance. Solid oral delivery systems are cheaply manufactured because they don't require sterile conditions (Patel et al., 2010). Many pharmaceutical dosages are administered in the form of liquids, powders, pills and granules. Some patients especially geriatric and pediatric have problems in swallowing of tablets and capsules (Dixit and Puthli, 2009). These types of patients are always unwilling to take solid preparations.

In this condition, oral fast dissolving drug delivery system is such a peculiar approach to increase patient compliance by its quality of rapid disintegration and selfadministration without swallowing and chewing (Bandari et al., 2008). Oral drug delivery has been changed from conventional dosage form to modified release dosage form and oral disintegrating tablets to the oral disintegrating films. Most disintegrating tablets are fragile and unsubstantial, which require special packaging for storage and transportation. But the oral films are more pliable and compliant and easily handled (Dixit and Puthli, 2009).

Oral disintegrating film or strip can be defined as, “A dosage for that employs a water dissolving polymer which allows the dosage form to quickly hydrate by saliva, adhere to mucosa, and disintegrates within a few seconds, dissolves and releases medication for oromucosal absorption when placed on tongue or oral cavity." The sublingual mucosa having thin membrane and large veins is more permeable (Barnhart and Sloboda, 2007b). It gives instantaneous bioavailability of drugs due to rapid blood flow.

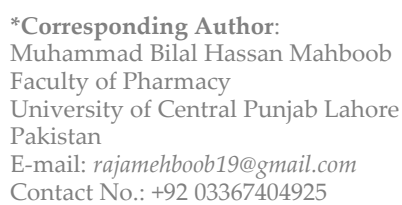

An oral film or strips are manufactured as a large sheet and then cut into individual dosage unit for packaging (Desai et al., 2012). Oral film used for local action in mouth such as local anesthetic for toothaches, oral ulcer, cold sores or teething etc. (Kumar et al., 2011). Many drugs like cough remedies, antiasthamatics, antihistaminic, erectile dysfunction drugs, sore throat, gastrointestinal disorders, nausea, pain and CNS drugs can be incorporated. Other applications include the preparation of caffeine strips, multivitamins, sleeping aid and snoring aid etc.

\section{Advantages}

Oral films have some special advantages over other oral dosage forms given as follows:

- Rapidly dissolved and disintegrated in the oral cavity because of large surface area which lowers dosage interval, improves onset of action, efficacy and safety profile of therapy.

- Oral films are more flexible, compliant and are not brittle as ODTS.

- $\quad$ Easily handled, storage and transportation.

- Accuracy in the administered dose is assured from every strip or film.

- Pharmaceutical companies and customers practically accepted OTFs as an alternative of conventional OTC dosage forms such tablets and capsules etc. (Frey, 2006).

- Oral film is desirable for patient suffering from motion sickness, dysphagia, repeated emesis and mental disorders.

- From commercial point of view, oral films provide new business opportunity like product differentiation, promotion etc. (Manivannan, 2009).

\section{Disadvantages}

The main disadvantage of this delivery system is we cannot incorporate high dose into strip or film. Novartis consumer health's Gas-x thin strip has loaded $62.5 \mathrm{mg}$ of simethicone per strip (Siddiqui et al., 2011), but there remain number of limitations with the use of film strips. 
Table 1: Different properties of oral films (Desai et al., 2012).

\begin{tabular}{llll}
\hline Properties & Flash Release Wafer & Mucoadhesive Melt Away Wafer & Mucoadhesive Sustained Release Wafer \\
\hline Area & $2-8$ & $2-7$ & $2-4$ \\
Thickness & $20-70$ & $50-500$ & $50-250$ \\
Structure & Film:single layer & Single or multilayer system & Multilayer system \\
Excipients & Soluble, highly hydrophilic polymers & Soluble, highly hydrophilic polymers & Low/ non-soluble polymers \\
Drug phase & Solid solution & Solid solution or suspended drug particle & Suspension or solid solution \\
Application & Tongue (upper palate) & Gingival or buccal region & Gingival (other region in the oral cavity) \\
Dissolution & Maximum 60 sec & Disintegration in a few minutes, forming gel & Maximum 8-10 hrs \\
Site of action & Systemic or local & Systemic or local & Systemic or local \\
\hline
\end{tabular}

\section{Classification of oral films}

There are three types of oral films:

1. Flash release

2. Mucoadhesive melt away wafer

3. Mucoadhesive sustained release wafers

Different properties of classification of oral films are summarized in table 1.

\section{Applications of oral films in drug delivery}

Oral drug delivery by sublingual, mucosal and buccal become preferable for therapies in which immediate absorption is required including those used to manage pain, allergies, sleep problems and CNS disorders. Topical applications, the oral films are ideal in the delivery of active agents like analgesic or antimicrobial ingredients for the care of wound and other applications. Gastroretentive dosage systems, poorly soluble and water soluble molecules of different molecular weights are found in film format (Barnhart and Sloboda, 2007a). Dissolution of oral films could be initiated by the $\mathrm{pH}$ or enzymatic secretion of GIT and are used to treat gastrointestinal disorders. Diagnostic devices, Oral films loaded with sensitive reagent to allow controlled release faced to biological fluid for separating multiple reagents to allow a timed reaction within diagnostic device (Meathrel and Moritz, 2007).

\section{ORAL STRIP FORMULATION COMPONENTS}

- Active pharmaceutical ingredients

- $\quad$ Strip forming polymers

- Plasticizers

- $\quad$ Sweetening agents

- Saliva stimulating agents

- Flavoring agents

- Coloring agents

- Stabilizing and thickening agents

\section{Active pharmaceutical ingredients}

The main disadvantage of oral strip/ film is the size of the dosage form due to which high dose could not be loaded. We incorporate $5 \% \mathrm{w} / \mathrm{w}$ to $30 \% \mathrm{w} / \mathrm{w}$ of active pharmaceutical ingredients (Kulkarni et al., 2003). For multivitamins, up to $10 \% \mathrm{w} / \mathrm{w}$ of dry film weight was loaded (Ali and Quadir, 2007). APIs can be milled, micronized or loaded in the form of nanocrystals or particles depending upon the ultimate release profile desired (Hariharan and Bogue, 2009). For bitter drugs taste required to be masked before incorporating APIs in the OS (Sohi et al., 2004). To enhance the taste different techniques are used but the simplest method includes mixing and co-processing of bitter testing API with excipient with good pleasant taste called as obscuration technique. Regiospecific delivery of the drugs would also be required in allergy, cough, sore throat and other local oral manifestations.
Suitable drug molecules that can be loaded in the oral films/strips are given in the table 2 .

\section{Strip forming polymers}

Polymers can be used alone or in contrast to get the required film properties for the preparation of oral film to prevent damage during handling and transportation (Corniello, 2006). At least $45 \% \mathrm{w} / \mathrm{w}$ of polymers should present because strip forming polymer is the important constituent of the OS (Franchiser et al., 2007). Generally, 60$65 \%$ of water soluble polymer is suitable for OS preparation with desired properties (Lydzinski et al., 2002).

Ability of polymers about formulation of desired strip (film forming capacity), visual appearance, disintegration time values are given in the table. Visual appearance of the film is transparent and free of bubbles necessary for aesthetic appeal of the films (Kulkarni et al., 2010).

Properties of different polymers used in the formulation of oral films are given in the table 3.

\section{Plasticizers}

Plasticizer can be used to improve the elasticity and decrease the fragility of film by decreasing the glass transition temperature of polymer. The choice of plasticizer depends on its compatibility with polymer and the solvent type (Banker, 1966). Most commonly used plasticizers are glycerol, propylene glycol, PEG, phthalate derivatives such as dimethyl, diethyl and dibutyl phthalate, citrate derivatives

Table 2: Suitable drug molecules that can be loaded in the oral film/ strip (Sohi et al., 2004).

\begin{tabular}{lll}
\hline Molecule & $\begin{array}{l}\text { Dose } \\
\text { (mg) }\end{array}$ & Therapeutic category \\
\hline Acrivastine & 8 & Antihistaminic \\
Azatidine maleate & 1 & Antihistaminic \\
Cetrizine & $5-10$ & Antihistaminic \\
Chlorpheniramine maleate & 4 & Anti-allergic \\
Diphenhydramine $\mathrm{HCl}$ & 25 & Antihistaminic \\
Dicyclomine & 25 & Muscle relaxant \\
Dextromethorphan $\mathrm{HCl}$ & $10-20$ & Cough suppressant \\
Desloratidine & 5 & Antihistaminic \\
Famotidine & 10 & Antacid \\
Flurazepam & $15-30$ & Anxiolytic, Anticonvulsant \\
Ketoprofen & $12.5-25$ & Anti-inflammatory \\
Lopramide & 2 & Anti-diarrheal \\
Loratidine & $5-10$ & Antihistaminic \\
Nitroglycerine derivatives & $0.3-0.6$ & Vasodilators \\
Nicotine & $1-15$ & Smoking cessation \\
Oxycodone & $2.5-10$ & Opioid analgesic \\
Omeprazole & $10-20$ & Proton pump inhibitor \\
Sumatriptane succinate & $35-70$ & Antimigraine \\
Tripalodine HCl & 2.5 & Antihistaminic \\
Zolmitriptan & 2.5 & Anti-migraine \\
\hline
\end{tabular}


Table 3: Properties of different polymers used in the formulation of oral films (Kulkarni et al., 2010).

\begin{tabular}{|c|c|c|c|}
\hline Polymer Used & $\begin{array}{l}\text { Disintegration } \\
\text { Time (sec) }\end{array}$ & Appearance & $\begin{array}{c}\text { Film Forming Ca- } \\
\text { pacity }\end{array}$ \\
\hline $\begin{array}{l}\text { HPMC E-15+ } \\
\text { PEG } 400\end{array}$ & 120 & Transparent & Good \\
\hline $\begin{array}{l}\text { HPMC E-15+ } \\
\text { Glycerin }\end{array}$ & 92 & Transparent & Good \\
\hline HPMC K4M & - & - & Very poor \\
\hline $\begin{array}{l}\text { HPMC E-15+ Pul- } \\
\text { lulan }\end{array}$ & - & - & Poor \\
\hline HPMC E-15+ PVA & 78 & Transparent & Average \\
\hline HPMC E-15+PVP & 67 & Transparent & Average \\
\hline $\begin{array}{c}\text { HPMC E- } \\
\text { 15+PVA+MCC }\end{array}$ & - & - & Poor \\
\hline HPMC E-15+MCC & 42 & $\begin{array}{l}\text { Semi transpar- } \\
\text { ent }\end{array}$ & Better \\
\hline PVA & 52 & Transparent & Average \\
\hline $\begin{array}{c}\text { PVA+PVP+ Glyc- } \\
\text { erine }\end{array}$ & 64 & Transparent & Average \\
\hline $\begin{array}{l}\text { PVA+PVP+ } \\
\text { PEG } 400\end{array}$ & 52 & Transparent & Average \\
\hline PVP & - & - & Very poor \\
\hline Pullulan+PVA & - & - & Very poor \\
\hline $\begin{array}{c}\text { Pullulan+ } \\
\text { Guar Gum+ Xan- } \\
\text { than Gum+ } \\
\text { Carragenon }\end{array}$ & 19 & Transparent & Best \\
\hline Gelatin & - & - & Very poor \\
\hline Eudragite RL-100 & - & - & Very poor \\
\hline
\end{tabular}

like tributyl, triethyl, acetyl citrate, triacetin and castor oil. $0-20 \% \mathrm{w} / \mathrm{w}$ plaster concentration is used by preventing cracking, splitting and peeling of strip (Rowe and Forse, 1980).

\section{Sweetening agents}

Sweeteners are the essential constituent of pharmaceutical product for pediatric patients. Generally, two types of sweeteners are most commonly used which are natural sweeteners and artificial sweeteners. Sucrose is the major source of sweeteners; dextrose, fructose glucose and maltose are also source of sweeteners. The use of natural sugar is limited in diabetic patients (Mennella and Beauchamp, 2008), that's why artificial sweeteners are most commonly used in pharmaceutical preparations. First generation artificial sweeteners include cyclamate and aspartame while second generation include acesulfame- $K$, sucralose, alitame and neotame (Prakash et al., 2008).

\section{Saliva stimulating agent}

To enhance the rate of production of saliva, saliva stimulating agents are added. Generally, acids such as citric acid, malic acid, lactic acid, ascorbic acid and tartaric acids are salivary stimulants. These agents are used in $2-6 \% \mathrm{w} / \mathrm{w}$ of weight of strip. Sweeteners also used as salivary stimulants (Mahaparale et al, 2012).

\section{Flavoring agents}

The choice of flavors depends on age, taste and liking of the people. Younger people like fruit punch, raspberry etc. while the geriatric patient prefer orange, lemon and mint flavor. The selection of flavor is done on the type of drug candidate. Almost 10\%w/w flavors are added in oral film preparations. Cooling agents can also be added to enhance the flavor strength (McGregor et al., 2004).

\section{Coloring agents}

When formulation ingredients or drug candidates are present in insoluble or suspension form pigments like titanium dioxide or FD\&C approved coloring agents which are incorporated up to $1 \% \mathrm{w} / \mathrm{w}$ (kumar Vishwakarma et al.).

\section{Stabilizing and thickening agents}

To improve the viscosity and consistency of formulation the stabilizing and thickening agents are incorporated. Natural gum, like xanthan gum, carragenan, locust bean gum and cellulose derivative are loaded up to $5 \% \mathrm{w} / \mathrm{w}$ (kumar Vishwakarma et al.).

\section{METHODS FOR THE PREPARATION OF}

\section{ORAL FILMS}

Various methods for producing oral films are classified as follows:

- Casting and drying: (a) solvent casting (b) semi-solid casting.

- Extrusion: (a) hot melt extrusion (b) solid dispersion extrusion

- Rolling method:

Casting and Drying

\section{a) Solvent- Casting Method}

The oral film is mostly prepared by using the solvent-extraction method, in which water soluble ingredients are dissolved to form a clear viscous solution. The active pharmaceutical ingredient and other agents are dissolved in small amount of solution and combine with bulk. This mixture is then added into aqueous solution. Remove entrapped air and resulting solution is casted as film and then dried which is then cut into pieces of the desired sizes (Sapkal et al., 2011).

\section{b) Semi-solid Casting:}

First of all, a solution of water soluble film forming polymer is prepared in semi solid casting method. Then resulting solution is added to insoluble polymer like cellulose acetate butyrate, cellulose acetate phthalate etc., prepared in sodium or ammonium hydroxide. Then add accurate amount of plasticizer to get gel mass. Finally cast gel mass into films by using heat controlled drums. The thickness of the film is about $0.015-0.05$.

\section{Extrusion}

\section{a) Hot-Melt Extrusion}

Hot melt extrusion is widely employed method to formulate granules, sustained release tablets; transdermal and transmucosal drug delivery system. Processing film involves shaping a polymer into a film by using the heating process. Filled the hopper with drug carrier mix and is conveyed, mixed and melted by the extruder. Then die shaped melt in the desired film form. Repka et al. prepared chlorpheniramine maleate films by hot melt extrusion method (Nagaraju et al., 2013). 


\section{b) Solid-Dispersion Extrusion}

In this method, drug is firstly dissolved in a suitable liquid solvent and then this solution is incorporated in melt of PEG below 70C. The selected solvent or drug could not be miscible with melt of PEG and polymorphic form of drug precipitated in solid dispersion may affected by solvent (Ravindran, 2011).

\section{Rolling method}

In rolling method, film is formulated by preparation of premix, by adding active and subsequent formation of film (Rathi et al., 2011). The pre-mix batch include film forming polymer, polar solvent and other ingredients except API added to the master batch feed tank. Then a predetermined amount of the master batch is fed by first metering pump and control valve. The desired amount of drug is added into mixer, and then blended for a sufficient time to form a homogenized matrix. A specific amount of matrix is fed into pan through second metering pump. The metering roller determined thickness of film. The film is finally formed on substrate and carrier away by the support roller. The wet is dried by using controlled bottom drying.

\section{QUALITY CONTROL TESTS FOR ORAL}

\section{DISINTEGRATING FILMS}

Medicated strips are characterized by the following quality control tests:

\section{Mechanical properties}

Thickness measured the thickness of strip by micrometer screw gauge at different stages to assure uniformity in the thickness. Dryness test eight stages of film drying process have been identified which are set-to-touch, dust-free, surface dry, dry-to-touch, dry-hard, dry-through, dry-torecoat and dry print-free. These tests are used to paint films but most of the studies can be adapted to evaluate pharmaceutical oral films (Sward, 1972). Tensile strength is a maximum stress applied to a point at which strip specimen break (DE et al.). It is calculated by applied load at rupture divided by the cross-sectional area of the strip by using following equation. In Percentage Elongation when stress is applied, a strip sample stretches and this is referred to as strain. Strain is basically the deformation of strip divided by original dimension of sample. Elongation of strip increases as plasticizer content increases (Fulzele $e t$ al., 2002). Tear Resistance of film is role of its extreme resistance to rupture. To measure the force to start the tearing, generally low rate of loading approximately $51 \mathrm{~mm} / \mathrm{min}$ is employed. The maximum force needed to tear the specimen is recorded in Newton (Kapadia et al., 2013). Elastic Modulus is the ratio of applied stress and corresponding strain in the region of approximately linear proportion of elastic deformation on the load displacement profile. Young's Modulus is used to determine stiffness of film. It is represented as ratio of applied stress over strain in the elastic deformation. Folding Endurance is calculated by repeated folding of the strip at same place until strip breaks. Many times, the film is folded without breaking is computed as the folding endurance value (Shinde et al., 2008).

\section{Morphology study}

Scanning electron microscopy (SEM) at a definite magnification is used to study the morphology of study (Mashru et al., 2005).

\section{Swelling Property}

By using simulated saliva solution, the swelling studies of film is carried out. Weighed every film sample and placed in pre-weighed stainless steel wire mesh. The mesh is dissolved in $15 \mathrm{ml}$ medium in plastic container. Determine increase in weight film at present time interval until constant weight is achieved (Peh and Wong, 1999).

\section{Contact Angle}

Goniometer determined the contact angle at room temperature. Put a drop of double distilled water on dry film surface. Image of water droplet recorded within $10 \mathrm{sec}$ of deposition by using digital camera. To determine angle, analyze digital picture. The contact angle was measured on both side of drop and averaged (Bettini et al., 2008).

\section{Disintegration time}

For fast disintegrating oral films, the disintegrating time limit of $30 \mathrm{sec}$ or less can be employed. But still no official guideline is present, this may be used as a qualitative guideline for quality control test. Generally, disintegration time for oral strip is 5-30sec (Gavaskar et al., 2010).

\section{Dissolution test}

Dissolution testing can be employed by using standard paddle or basket apparatus. The choice of dissolution medium depends on the sink condition and high dose of active ingredient (Dixit and Puthli, 2009). When paddle apparatus is used sometimes dissolution test having problems because of tendency of strip to float on dissolution medium (Nishimura et al., 2009).

\section{Drug content and content uniformity}

Any standard assay methods described for the specific API determine the drug content. Content uniformity is estimated by calculated the API content in individual film. Content uniformity is limited to $85-115 \%$.

\section{Organoleptic evaluation}

Most of the people accepted products that possess features of sweetness and flavor. Special controlled human taste panels are used for product evaluation. For this purpose, invitro methods of utilizing taste sensors, specially designed apparatus and drug release by modified pharmacopoeial methods are used (Mashru et al., 2005). To differentiate between sweetness level in taste making formulation, experiments by using electronic tongue measurements were performed (Anand et al., 2007).

\section{Stability testing}

According to ICH guidelines Oral wafers have been stored under controlled conditions of $25^{\circ} \mathrm{C} / 60 \% \mathrm{RH}$ as well as $40^{\circ} \mathrm{C} / 75 \%$ over a period of 12 months. During storage, oral wafers should be checked properly for their morphological properties, mass thickness, reduction of film thickness, tensile properties, water content and dissolution behavior (Murray et al., 2004).

\section{MARKETED PRODUCTS OF ORAL FILMS}

Different products of oral films are summarized in the following table 4 . 
Table 4: Marketed Products of Oral Films (Arya et al., 2010).

\begin{tabular}{|c|c|c|}
\hline Product category & Ingredients & Indication /Application \\
\hline 1. Bio Films & & \\
\hline Energy boosters & Caffeine, green tea extract and guarana & The product maintains the energy level \\
\hline Saliva promoting strip & Fruit acid extract & $\begin{array}{l}\text { It is used in the dry mouth as a side effect } \\
\text { of the other medication }\end{array}$ \\
\hline Detoxification strip & Green tea extract & $\begin{array}{l}\text { Green tea has been used as a traditional } \\
\text { medicine commonly used in blood sugar, } \\
\text { wound healing, regulating body tempera- } \\
\text { ture and promoting healthy digestion. }\end{array}$ \\
\hline $\begin{array}{l}\text { Breath freshener strip (anti-bacterial } \\
\text { strip) }\end{array}$ & $\begin{array}{l}\text { It contains mint flavor and anti-bacterial agent, cetylpyri- } \\
\text { dinium chloride }\end{array}$ & $\begin{array}{l}\text { It is used as mouth freshener and to stop } \\
\text { bad odor of breath. }\end{array}$ \\
\hline Male vitality strip & Macroot extract and saberian ginseng, cannamint flavor & $\begin{array}{l}\text { It is used as an aphrodisiac and improves } \\
\text { the libido in males. }\end{array}$ \\
\hline Female vitality strip & Botanical ingredients such as passion flower and damiana & $\begin{array}{l}\text { It is used to improve general wellbeing, in- } \\
\text { crease energy and enhance mood }\end{array}$ \\
\hline Vitamins and food supplements & Various vitamins, minerals and supplements & $\begin{array}{l}\text { It is used for those patients who don't like } \\
\text { to pop up tablets or soluble supplements }\end{array}$ \\
\hline Appetite suppressants & Fucusvesiculosus, guarana extract and garciniacambogia & $\begin{array}{l}\text { Top selling natural ingredients used for } \\
\text { weight loss, cambogia helps to reduce the } \\
\text { food intake by suppressing appetite }\end{array}$ \\
\hline
\end{tabular}

\section{Bio Delivery Sciences International}

Onsolis

BEMA buprenorphine

Fentanyl /buccal soluble film

Buprenorphine
Pain in Opioid tolerant patients

Therapeutic alternative for patient with incomplete pain relief or those unable to tolerate

\section{CNS Stimulant}

Antihistaminic

Anti tussive agent used to prevent cough

Needed for formation of healthy red blood cells and used in anemia

Allergy

Peripheral neuropathy, diabetic neuropathy

\section{Innozen Inc}

Chloraseptic relief strip

Chloraseptic kids sore throat relief strips

Suppress cough strip with Dextromethorphan

Suppress cough strip with menthol
Benzocaine 3mg, BHT, corn starch, erythritol, FD\&C Red 40, Occasional minor irritation, pain, sore hydroxypropyl methylcellulose mallicacid, menthol monoam- throat and sore mouth monium glycyrrhizinate, cherry flavor, polyethyleneoxide, sucralose

Benzocaine $2 \mathrm{mg} \&$ menthol, grape flavor,BHT,cornstarch,erythritol,FD\&C Red 40,hydroxypropyl methylcellulose, mallicacid,menthol,menthol,mono ammonium glycyrrhizinate, polyrthyleneoxide,sucralose

- Dextromethorphan hydro bromide $2.5 \mathrm{mg}$, asulfame potassivors, pectin, peppermintoil,ucralose,sugar, water
Occasional minor irritation, pain, sore throat and sore mouth

Temporarily suppresses cough due to minor throat and bronchial irritation associated with cold or inhaled irritants

Artificial flavors, ascorbic acid, aspartame, asulfame potassium, Temporarily suppresses cough due FD\&C yellow 5, carrageenan, diglycerides, fatty acid esters, glycerin, menthol, sorbitan, monolaurate, sorbitol, spices, starch, water

to minor throat and bronchial irritation associated with cold or inhaled irritants 


\begin{tabular}{ll}
\hline Product category & Ingredients \\
\hline $\begin{array}{ll}\text { 5. Labtec Gmb H } \\
\text { Ondensetron rapid film }\end{array}$ & Ondensetron $4 \mathrm{mg}$ and $8 \mathrm{mg}$ \\
Donezepil rapid film & DonezepilHcl $5 \mathrm{mg}$ and $10 \mathrm{mg}$
\end{tabular}

\section{Paladin Labs(bioenvelop)}

Smoking cessation

Teeth whitening

Food supplements

Minerals

Multivitamins for kids and adults

Natural products

\section{Pfizer Inc}

Listerine pocketpaks

\section{Prestige Brands}

Little cold sore throat strip

Chloraseptic relief strip

\section{Novartis pharmaceuticals}

Day time Triaminic thin strip cold \& cough

Night time Triaminic thin strips cold \& cough

Triaminic thin strip long acting cough

Nicotine

Benzocaine, caffeine, melatonin, menthol, vipocetina

Chromium

B6, B12, C:D3 for kids D3 for adults

Ginseng and guarana

Fresh citrus, cinnamon, cool mint and fresh burst

Ascorbic acid, pectin

Benzocaine, menthol

\section{Indication /Application}

It is used to prevent chemotherapy and radiation induced nausea, vomiting

It is used in the treatment of mild to moderately severe dementia of the Alzheimer's type

To reduce smoking habit

Life style improvement product

Neutraceuticals

Mineral supplements

Multivitamins supplements

Aphrodisiac, appetite reducer

Dissolve instantly and kill $99 \%$ of bad breath germs

Cold/allergy

Sore throat

Dextromethorphan $3.67 \mathrm{mg}$, phenylephrineHcl2.5mg, acetone, al- It is used as nasal decongestant cohol, FD\&C blue I, FD\&CRed40, flavors,

hypromellose,isopropylalcohol, microcrystalline cellulose, polacrillin, polyethylene glycol, propylene glycol, purified water sodium polystyrene sulfonate, sucralose, titanium dioxide

Diphenhydramine $\mathrm{HCl} 12.5 \mathrm{mg}$, phenylephrineHcl5mg, acetone, Cough suppressant, nasal decongestant. It FD\&C blue I, FD\&CRed40, flavors, hypromellose, maltodextrin, temporarily relieves cough due to minor mannitol, polyethylene glycol, propylene glycol, purified water, throat and bronchial irritation as may ocsodium polystyrene sulfonate, sucralose, titanium dioxide cur with a cold

Dextromethorphan5.5mg, acetone, alcohol, dibasic sodium phos-It temporarily relieves cough due to miphate, FD\&CRed40, flavors, hypromellose, isopropylalcohol, nor throat and bronchial irritation as may microcrystalline cellulose, polacrillin, polyethylene glycol, pro- occur with a cold pylene glycol, purified water, sodium polystyrene sulfonate, sucralose,titanium dioxide

Triaminic thin strip cough \& runny nose

Diphenhydramine $\mathrm{HCl} 12.5 \mathrm{mg}$, phenylephrineHcl5mg, acetone, It reduces cough due to minor throat and FD\&C blue I, FD\&CRed40, flavors, hypromellose, maltodextrin, bronchial irritation. It relieves itchy, wamannitol, polyethylene glycol, propylene glycol, purified water, tery eyes due to hay fever sodium polystyrene sulfonate, sucralose, titanium dioxide

Triaminic thin strip cold with stuffy phenylephrineHcl2.5mg, acetone, FD\&C blue I, FD\&CRed40, fla-It temporarily relieves nasal and sinus nose vors, hypromellose, isopropyl alcohol, maltodextrin polyethylene glycol, propylene glycol, purified water, sodium polystyrene sulfonate, sucralose, titanium dioxide

Theraflu daytime thin strip

Dextromethorphan14.8mg, phenylepherine Hcl10mg, acetone, It reduces cough due to minor throat and alcohol, FD\&CRed40,flavors,hypromellose,isopropyl alcohol, bronchial irritation polyethyleneglycol,sodium polystyrene sulfonate, polacrilin and sucralose

Theraflu night time thin strips

Diphenhydramine $\mathrm{HCl} 25 \mathrm{mg}$, phenylephrineHcl 10mg, acetone, It is used for nasal congestion, runny FD\&C blue I, flavors, hypromellose, mannitol, polyethylene gly- nose, sneezing, itchy nose and throat etc. col, propylene glycol, polystyrene sulfonate, polacrilin and sucralose

Theraflu thin strips- Multisymptoms Diphenhydramine $\mathrm{HCl} 25 \mathrm{mg}$, acetone, FD\&CRed40, flavors, It temporarily relieves nasal and sinus hypromellose, maltodextrin, polyethylene glycol, propylene gly- congestion col, purified water, sodium polystyrene sulfonate, sucralose, titanium dioxide 


\section{REFERENCES}

Ali, S., Quadir, A., (2007). High molecular weight povidone polymer-based films for fast dissolving drug delivery applications. Drug Delivery Technology, 7(6), 36-43.

Anand, V., Kataria, M., Kukkar, V., Saharan, V., Choudhury, P.K., (2007). The latest trends in the taste assessment of pharmaceuticals. Drug Discovery Today, 12(5), 257-265. [DOI]

Arya, A., Chandra, A., Sharma, V., Pathak, K., (2010). Fast dissolving oral films: An innovative drug delivery system and dosage form. International Journal of Chem Tech Research, 2(1), 576-583.

Bandari, S., Mittapalli, R.K., Gannu, R., Rao, Y.M., (2008). Orodispersible tablets: An overview. Asian journal of pharmaceutics, 2(1), 2. [DOI]

Banker, G.S., (1966). Film coating theory and practice. Journal of pharmaceutical sciences, 55(1), 81-89. [DOI]

Barnhart, S., Sloboda, M., (2007a). Dissolvable films the future of dissolvable films. Drug Dev tech, 1, 34-35.

Barnhart, S., Sloboda, M., (2007b). The future of dissolvable films. Drug Delivery Technol, 7(8), 34-37.

Bettini, R., Romani, A.A., Morganti, M.M., Borghetti, A.F., (2008). Physicochemical and cell adhesion properties of chitosan films prepared from sugar and phosphate-containing solutions. European Journal of Pharmaceutics and Biopharmaceutics, 68(1), 74-81. [DOI]

Corniello, C., (2006). Quick dissolving strips: From concept to commercialization. Drug Del. Technol, 6(2), 68-71.

De, P.K., Desu, R.K., Bonthagarala, B., Nama, S., Nagalakshmi, A., Formulation and evaluation of

Desai, P.P., Date, A.A., Patravale, V.B., (2012). Overcoming poor oral bioavailability using nanoparticle formulations-opportunities and limitations. Drug Discovery Today: Technologies, 9(2), e87-e95. [DOI]

Dixit, R., Puthli, S., (2009). Oral strip technology: Overview and future potential. Journal of controlled release, 139(2), 94-107. [DOI]

Franchiser, C., Slominski, G., Meyer, S., (2007). Disintegrable oral films. US Patent, 202057.

Frey, P., (2006). Film strips and pharmaceuticals. Pharma. Mfg. \& Packag. Sourcer, winter, 92

Fulzele, S., Satturwar, P., Dorle, A., (2002). Polymerized rosin: Novel film forming polymer for drug delivery. International journal of pharmaceutics, 249(1), 175-184. [DOI]

Gavaskar, B., Kumar, S.V., Sharan, G., Rao, Y.M., (2010) International journal of pharmacy and pharmaceutical sciences. Int J Pharmacy and Pharm Sci, 2(3), 29-33.

Hariharan, M., Bogue, A., (2009). Orally dissolving film strips (odfs): The final evolution of orally dissolving dosage forms. Drug Deliv Technol, 9(2), 24-29.

Kapadia, Y.D., Trambadiya, D.A., Patel, A.V., Patel, V.P., (2013). Formulation and evaluation of fast dissolving sublingual film of metoprolol succinate. Pharma Science Monitor, 3(3).

Kulkarni, A., Deokule, H., Mane, M., Ghadge, D., (2010). Exploration of different polymers for use in the formulation of oral fast dissolving strips. J Curr Pharm Res, 2(1), 33-35.

Kulkarni, N., Kumar, L., Sorg, A., (2003). Fast dissolving orally consumable films containing an antitussive and a mucosa coating agent. Google Patents.

Kumar, V.D., Sharma, I., Sharma, V., (2011). A comprehensive review on fast dissolving tablet technology.

Kumar Vishwakarma, P., Deshkar, P., Lal, N., Dhudkewar, S., Orally disintegrating strips (ods) convenience of liquid dosage form and dose accuracy of solid dosage form

Lydzinski, S., Manegold, T., Solarek, D., Tsai, J., Puglisi, C., (2002). Oral film which contains starch as main component; useful for delivering a variety of agents to humans and other animals. Google Patents.
Mahaparale, M.A., Shivnikar, S.S.T., Pawar, K.V., Prashant, N., (2012) Fast dissolving oral films: An innovative drug delivery system. IJRRPAS, 2(3).482-496

Manivannan, R., (2009). Oral disintegrating tablets: A future compaction. Drug Invention Today, 1(1), 61-65.

Mashru, R., Sutariya, V., Sankalia, M., Parikh, P., (2005). Development and evaluation of fast-dissolving film of salbutamol sulphate. Drug development and industrial pharmacy, 31(1), 25-34. [DOI]

Mcgregor, R., Homan, H., Gravina, S., (2004). Fast dissolving film delivery of nucleotides that inhibit the unpleasant taste of bitter tasting medications. WO Patent, 19885.

Meathrel, B., Moritz, C., (2007). Dissolvable films and their potential in ivds. IVD Technol, 13(9), 53-58. [DOI]

Mennella, J.A., Beauchamp, G.K., (2008). Optimizing oral medications for children. Clinical therapeutics, 30(11), 2120-2132.

Murray, O.J., Dang, W., Bergstrom, D., (2004). Using an electronic tongue to optimize taste-masking in a lyophilized orally disintegrating tablet formulation-the electronic tongue technology provides a technically suitable and cost-effective. Pharmaceutical Technology, 23, 42.

Nagaraju, T., Gowthami, R., Rajashekar, M., Sandeep, S., Mallesham, M., Sathish, D., Shravan Kumar, Y., (2013). Comprehensive review on oral disintegrating films. Current drug delivery, 10(1), 96-108. [DOI]

Nishimura, M., Matsuura, K., Tsukioka, T., Yamashita, H., Inagaki, N., Sugiyama, T., Itoh, Y., (2009). In vitro and in vivo characteristics of prochlorperazine oral disintegrating film. International journal of pharmaceutics, 368(1), 98-102. [DOI]

Patel, A.R., Prajapati, D.S., Raval, J.A., (2010). Fast dissolving films (fdfs) as a newer venture in fast dissolving dosage forms. International journal of drug development and research, 2(2), 232-246.

Peh, K.K., Wong, C.F., (1999). Polymeric films as vehicle for buccal delivery: Swelling, mechanical, and bioadhesive properties. J Pharm Pharm Sci, 2(2), 53-61. PMid:10952770

Prakash, I., Dubois, G., Clos, J., Wilkens, K., Fosdick, L., (2008). Development of rebiana, a natural, non-caloric sweetener. Food and Chemical Toxicology, 46(7), S75-S82. [DOI]

Rathi, V., Senthil, V., Kammili, L., Hans, R., (2011). A brief review on oral film technology. International Journal of Research in Ayurveda \& Pharmacy, 2(4).

Ravindran, C.A., (2011). Pelagia research library. Der Pharmacia Sinica, 2(4), 218-240.

Rowe, R., Forse, S., (1980). The effect of polymer molecular weight on the incidence of film cracking and splitting on film coated tablets. Journal of Pharmacy and Pharmacology, 32(1), 583-584. [DOI]

Sapkal, N.P., Kilor, V.A., Daud, A.S., Bonde, M.N., (2011). 1gurunanak college of pharmacy, nari, nagpur-26, india; 2zim laboratories ltd., nagpur, india; corresponding author e. Mail: Minal2108@ gmail. Com. Journal of Advanced Pharmaceutical Research, 2(2), 102-109.

Shinde, A.J., Garala, K.C., More, H.N., (2008). Development and characterization of transdermal therapeutics system of tramadol hydrochloride. Asian journal of pharmaceutics, 2(4), 265. [DOI]

Siddiqui, M.N., Garg, G., Sharma, P.K., (2011). A short review on-a novel approach in oral fast dissolving drug delivery system and their patents. Advances in Biological Research, 5(6), 291-303.

Sohi, H., Sultana, Y., Khar, R.K., (2004). Taste masking technologies in oral pharmaceuticals: Recent developments and approaches. Drug development and industrial pharmacy, 30(5), 429-448. [DOI]

Sward, G., (1972). Drying time. Paint Testing Manual-physical and chemical examination of paints varnishes lacquers, and colors, 13th Ed. American Society for Testing and Materials, 268. [DOI] 